to make treatment decisions. Our feeling is that we still need to question our practice even when it is well-established.

In conclusion, the review neither discourages nor encourages the extraction of primary canines. It does clarify the need for well designed randomised clinical trials on this topic. I suggest that the review is read in its entirety. If anyone is interested in carrying out a randomised clinical trial on this subject, then I hope our systematic review is of help.

N. Parkin

On behalf of the authors

1. Parkin N, Benson P E, Shah A, Thind B et al. Extraction of primary (baby) teeth for unerupted palatally displaced permanent canine teeth in children. Cochrane Database Syst Rev 2009; (2): CD004621.

2. Ericson S, Kurol J. Early treatment of palatally erupting maxillary canines by extraction of the primary canines. Eur J Orthod 1998; 10: 283-295.

3. The management of the palatally ectopic maxillary canine. RCS Guidelines, 1997 (revised 2004).

DOI: $10.1038 /$ sj.bdj.2009.1142

\section{DISPOSED TO ADIPOSE}

Sir, I read with interest the article Obesity and dentistry: a growing problem (BDJ 2009; 207: 171-175). This was timely for me as I also attended a clinical presentation by Professor Goran Dahloff at the FDI World Dental Congress in Singapore in September, entitled Lifestyle and obesity - the link to general disease and oral health.

Adipose tissue is loose connective tissue composed of cells called adipocytes and secretes adipokines in amounts proportional to the amounts of adipose tissue present. Adipokines affect the metabolism of the body and are thought to contribute to low grade systemic and vascular inflammation due to accumulation of gram negative bacteria and inflammatory mediators. Increasing body fat may stimulate a hyper inflammatory response as noted in periodontal disease. Obesity may have the potential for transforming the host's immunity and inflammatory system, causing the patient to be more at risk to the effects of microbial plaque.

Obesity is also associated with type 2 diabetes mellitus which results from inadequate insulin secretion to sustain normal metabolism and obese patients require more insulin to achieve this. The cytokine TNF, secreted by adipose tissue, is assumed to be critical in the pathogenesis of non-insulin dependent diabetes mellitus and in insulin resistance. Patients with type 2 diabetes are known to be prone to periodontal disease and obesity is also a risk factor for this and periodontitis.

I believe that obesity could therefore present dentistry with an opportunity to contribute to public health. Preventive interventions with a focus on children would be the key to health before obesity can cause the many medical conditions mentioned in the $B D J$ paper: hypertension, cardiovascular disease, diabetes mellitus, sleep breathing disorder, cancer, fatty liver disease, gall bladder disease, gastrooesophageal reflux disease, osteoarthritis and reproductive problems. Dental professionals in primary dental care are well placed and could be central in children's obesity services in Primary Care Trusts Healthy Weight Healthy Lives clinical pathways. Similarly, a reverse process could take place with obese children with dental caries referred to primary dental care by both health and non-healthcare professionals such as school nursing teams, community paediatricians, dieticians, psychologists, paediatricians, healthy schools teams, school sports coordinators and secondary care clinicians.

P. Wee, Camden DOI: 10.1038/sj.bdj.2009.1143

\section{FOLK REMEDY}

Sir, I write in response Dr Ballal's letter on oil pulling (BDJ 2009; 207: 193). Oil pulling therapy with sesame oil has been extensively used as a traditional Indian folk remedy for many years for strengthening teeth, gums and jaws and to prevent decay, oral malodour, bleeding gums, dryness of the throat and cracked lips. ${ }^{1}$ The concept of oil pulling therapy is not new and it has been discussed in the Ayurvedic text, Charak Samhita as 'Kavala Graha' or 'Kavala Gandoosha'. However, there is no scientific proof to support this therapy as a preventive adjunct, with online searches showing only testimonies and literature on personal experiences. With this in mind, randomised controlled pilot trials were conducted in Meenakshi Ammal Dental College, Chennai, India to assess the effect of oil pulling therapy on caries, gingivitis and halitosis.
A study group used oil pulling with a positive control group using chlorhexidine mouthwash. Both were equally effective in reducing Streptococcus mutans count over a six-month period and were better than tooth brushing alone. ${ }^{2,3}$ There was no significant reduction in the DMF scores in either group after a follow-up period of one year. However, there was a statistically significant reduction of the pre- and post-values of the plaque and modified gingival index scores with a considerable reduction in the total colony count of the microorganisms in both the study and the control groups. Additionally. there was a definite reduction in the organoleptic scores and BANA test scores in both groups.

Oil pulling promises to be an effective preventive home therapy to maintain oral hygiene and research is currently in progress to discover its exact mechanism of action, which could open new doors in the field of research in oral health care.

\section{S. Asokan, Chennai}

1. Asokan S. Oil pulling therapy. Indian J Dent Res 2008; 19: 169.

2. Asokan S, Rathan J, Muthu M S, Rathna Prabhu V et al. Effect of oil pulling on Streptococcus mutans count in plaque and saliva using Dentocult SM Strip mutans test: A randomized, controlled, triple blind study. J Indian Soc Pedod Prev Dent 2008; 28: 12-17.

3. Asokan S, Emmadi P, Chamundeswari R. Effect of oil pulling on plaque induced gingivitis: a randomized, controlled, triple-blind study. Indian J Dent Res 2009; 20: 47-51.

DOI: 10.1038/sj.bdj.2009.1144

\section{AVERTING DAMAGE}

Sir, I refer to the letter entitled Odd practice (BDJ 2009; 207: 464-465) and would like to remind readers that atheromatous blockage is not confined to arteries but is at least as important as a neurological risk factor in the internal jugular vein. ${ }^{1}$ Early warning of any blockage of blood supply to or drainage from the brain is vital to avert long-term neurological damage and any method that shows this is welcome.

\section{A. Carmichael By email}

1. Zamboni P, Menegatti E, Galeotti R, Malagoni A M et $a l$. The value of cerebral Doppler venous haemodynamics in the assessment of multiple sclerosis. J Neurol Sci 2009; 282: 21-27.

DOI: 10.1038/sj.bdj.2009.1145 